\title{
A Framework for Surface Modification by Electrical Discharge Coating using Variable Density Electrodes
}

\author{
Mohd. Yunus $\mathrm{Khan}^{1 *}$, P. S. Rao ${ }^{1}$, and B.S. Pabla ${ }^{1}$ \\ ${ }^{1}$ Department of Mechanical Engineering, National Institute of Technical Teachers' Training and Research (NITTTR), Chandigarh, \\ India
}

\begin{abstract}
Surface modification is the process of altering physical or chemical characteristics of the workpiece surface. In this paper, various surface modification techniques have been discussed. One of the most appropriate surface modification technique is electrical discharge coating (EDC), in which the hard material is made to deposit onto the work-piece in a state of reverse polarity condition. Different mechanisms of carrying out EDC are presented. Deliberate material transfer takes place by using electrodes or by dispersant of metal powders into the di-electric. A detailed review of the literature on the theme of surface modification through the EDC has been conducted. In last, a framework for conducting surface modification by EDC employing using density electrodes of same material is presented.
\end{abstract}

\section{Introduction}

Electrical discharge machining (EDM) also referred as spark erosion is widely accepted un-conventional method used to machine difficult to machine material by the traditional methods. In spark erosion process, desired shape is developed using series of recurring sparks between work-piece and tool, separated by dielectric medium and subjected to voltage difference. The process is used to machine hard materials [1,2].

Earlier EDM process was confined for machining materials which are electrically conductive but now with technological advancement ceramics and composites can be machined [3]. Spark erosion is widely used in producing moulds, dies, automobile, biotechnology, aerospace industries etc. Parts having intricate shapes and contours, specific dimensions can be easily developed by EDM process [1,3]. Significance of this process is that tool and work-piece stay contactless [4] and free from mechanical stresses [4, 5]. Material removal rate (MRR), tool wear rate (TWR), surface roughness (SR) etc. are the output variables which helps in assessment of EDM performance [3].

EDM process can be employed for surface modification where tool material is transferred to the work sample. This process is called as electrical discharge coating (EDC) [6]. The process can be executed on ordinary EDM under negative polarity condition i.e. tool is made anode while work piece cathode $[7,8]$. When the electric sparks are created in these conditions, tool will erode and settle onto the work-piece with suitable di-electric fluid. In every spark, the material of the work sample gets solidified by fast cooling as a result of the cold di-electric medium. This allows the transferred material of the tool to produce a coating on the work-piece [9]. EDC can result in improvement of properties like hardness, corrosion and wear resistance, with no appreciable change in the bulk characteristics of work-piece material $[6,7,10]$. Hence, electro discharge coating has the potential of turning into a useful substitute for surface modification method.

\section{Purpose of Surface Modification Process}

Surface modification is the process of altering physical or chemical characteristics of the work-piece surface. It is mainly achieved by physical or chemical treatments. In the chemical treatment, the surface is plunged into chemically active solutions. On the other hand, in physical technique the surface is subjected to extremely energetic charges or other physical species [11]. Practically all ceramics, polymers and composites can be coated with similar or dissimilar material. There is technological need for developing new technique of applying coatings, to improve existing techniques and to identify new applications. Hence, surface modification techniques have developed quickly to bring a wide range of quality and cost effectiveness. Immense accessibility

*Corresponding author: yunus.mech19@,nitttrchd.ac.in 
of coating techniques of wide ranging complexities are capable of depositing a number of coatings and guarantees that items of all shape and size can be coated economically.

The main purposes of surface modification are:

1. To embellish the surface quality of the material.

2. To enhance important properties of material.

3. To enhance bio-compatibility and surface wettability if needed for medical application. [12]

4. To clean the surface of the part. To remove dust, dirt and scale left behind after casting and forging.

5. To protect the surface from environment.

6. To give better appearance to the component.

\section{Surface Modification Technologies}

Number of coating methods is accessible for surface alloying or surface alteration. Important surface modification techniques are discussed below.

\subsection{Physical Vapor Deposition (PVD)}

In this technique, a thin layer is deposited by the condensing a vaporized form of the required film material on the work-piece surface. The process includes high-temperature vacuum evaporation followed by condensation [13]. This process typically operates at extremely high temperatures and needs vacuum device. The pace of process is relatively slow and cost of the equipment is significant. [9]

\subsection{Plasma Arc Coating}

Plasma arc coating involves spraying of a work-piece with molten or semi-molten material to achieve a hard layer which can protect the surface from oxidation and corrosion. Plasma coatings are obtained by a high temperature technique that requires injection of powdered material into a plasma flame. This material is quickly heated and is then accelerated toward the surface to be coated. Once it reaches the surface, it cools, forming a hard layer on the substrate. The high temperatures involved in this process permit the use of high melting point materials. The equipments used for this process needs automatic gun manipulator. [14]

\subsection{Laser Coating}

Laser coating or laser cladding is used to improve topography, phase composition and surface properties [15]. This method includes the feeding of a stream of metal powder or wire into a molten pool that is made by laser beam as it scans across the target work-piece, depositing a layer of the selected material. Operational cost of this process is high due to cost of laser.

\subsection{Electro-plating}

Electro-plating is an electrolytic process in which metal ions in the electrolyte solution are deposited on the cathode. So, anode is made of metal to be coated while work material is cathode. DC supply from external supply passes through electrolyte solution. The electrolytes used are aqueous solution of acids, bases or salts. This process is limited to only certain types of materials. Further, process is quite slow and the adhesion of coating with substrate isn't acceptable. [14]

\subsection{Chemical Vapor Deposition}

Chemical Vapor Deposition (CVD) is used for producing strong solid materials [9]. This process includes the progression of gas into a chamber containing sample to be coated [16]. As it passes through or comes into contact with the heated substrate, it reacts or decomposes and forms a solid phase that settles onto the substrate [9]. CVD process is very slow. This method is restricted to small size items only. There are risks associated with the use of harmful, corrosive and flammable gases [9, 17]. The process requires sophisticated reactor which restricts its application in industries [9].

\subsection{Electrical Discharge Coating}

Electrical Discharge Coating is an unconventional technique wherein hard layers are obtained on the substrate surface [17]. This method doesn't require any special arrangement and can be easily conducted on conventional EDM machine with reverse polarity conditions $[7,8]$. The material is expelled from the tool and accumulates on the work-piece [18]. EDC offers numerous advantages over other methods of coating. The EDC process is gaining popularity because of its simplicity [19].

\section{Advantages and Limitations of EDC}

The electrical discharge coating is used for producing hard and wear resistant coatings in different industries [10]. This method offers several benefits over other coating methods. Some of the advantages are:

1. This method is cost effective and doesn't require high investment cost [20].

2. There is no need for complex equipment such as vacuum apparatus or high temperature device [21].

3. Process of EDC may be performed on a conventional machine [22] under reverse polarity condition [7].

4. It is easy to create hard coats of various materials on the work-piece surface [7]. Range of materials can be used [6].

5. Coatings can be provided at various points on the work-piece and its depth can be easily administered. [22]

Limitation of EDC is that in some cases few microcracks were observed on surface of work-piece. [6]

5 Applicability of EDC 
Electrical discharge coating is used extensively for its minimalism, cost effectiveness and simple setup. Applicability of this process is discussed below:

1. This method can be applied to roll texturing and roll recovery by enhancing the wear resistance of the material. [23]

2. It finds application in repairing of the worn parts by providing a protective coatings [24]

3. EDC process is used in bio-medical field to improve biomechanical properties and produces crack free surface. [25]

4. It is used in various industrial which includes tool, die and mould making industries.

5. This process is also used in automobile industry and turbine blade manufacturing. [6]

\section{Different Mechanisms of Electrical Discharge Coating}

Surface modification by EDC is a means for improving the mechanical, chemical and tribological characteristics of the work-piece. The basic aim is transfer of the tool material onto the work-piece in order to get hard, wear and corrosion resistance layer [26]. Surface alteration by EDC can be achieved by different ways. These methods and their mechanism are summarized in following headings.

\subsection{Conventional Tools}

Electrical discharge surface modification can be carried out by solid electrodes. When solid electrode are used as cathode and work-piece as anode with suitable HC dielectric fluid, the metal carbide of the work material is formed as a result of the reaction of the substrate with the decomposed carbon from di-electric in the process. Under this condition, wear resistant coating can be developed. Commonly used materials for this process are $\mathrm{Cu}-\mathrm{W}$, Ti, graphite etc. [9]

\subsection{Powder Metallurgy Tools}

Surface modification can be obtained on EDM machine using tools synthesized by powder metallurgy technique under condition of inverse polarity. Low density of tool will be helpful in achieving desired coating. Hard carbides are created by the reaction of decomposed carbon particle (C) from the di-electric at high temperature, with the worn electrode material (M). The carbide formed (MC) is slowly piled up on the work material and a thick hard layer is formed over it. The characteristics of powder compaction play significant role in this process. The properties of tool can be changed by varying composition of the powders, compaction pressure and the sintering temperature. The commonly used powder materials include $\mathrm{Ti}$, Ti-C, $\mathrm{WC} / \mathrm{Co}, \mathrm{Ni} / \mathrm{Co}$ etc. The merit of using $\mathrm{P} / \mathrm{M}$ tool is that, it can be easily fabricated using different compositions and of different shape. [14]

\subsection{Powder-Mixing Method}

EDC can also be achieved by mixing suitable powder in the di-electric fluid [10]. When spark is created between the tool and work-piece, reaction occurs amidst powder and carbon obtained due to decomposition of di-electric. As a result of which a layer of hard carbide forms over the wok-piece [14]. In the case of surface modification using powder-mixed di-electric, it is suggested to adjust reverse polarity [9]. The common powders include $\mathrm{Si}$, $\mathrm{Ni}, \mathrm{Al}, \mathrm{Ti}, \mathrm{W}$ etc [27].

\section{Studies on Electrical Discharge Coating (EDC)}

Experiments related to surface modification using electrical discharge coating has been conducted by several investigators over the years. Numerous surface changes have been observed and presented. By considering suitable input variables, the desired surface modification is achieved. Summary of various studies conducted in the area of EDC are summarized below.

Fukuzawa et al. (1993) [28] achieved surface modification of SUS-304 stainless steel using EDM with a sialon-TiN ceramic electrode. They observed that the surface modified layer improved the corrosion and wear resistance. Tsunekawa et al. (1994) [29] modified the surface of aluminum using Ti contained in the tool and carbon decomposed from di-electric fluid. A composite layers $100 \mu \mathrm{m}$ thick was achieved in a short time. Soni and Chakraverti (1996) [30] assessed the alteration in the chemical composition of re-solidified layers of $\mathrm{Cu}-\mathrm{W}$ tool and high carbon high chromium die steel work-piece. It was observed that a significant quantity of the tool material migrated towards work sample and vice-versa and got combined in the resolidified layer. Lin et al. (2001) [31] evaluated impact of using combination of EDM and ultrasonic vibration on Al-Zn-Mg alloy. A modified coating $80 \mu \mathrm{m}$ deep was obtained on the workpiece surface and this layer improved the hardness and wear resistance.

Uno et al. (2001) [32] investigated surface modification of aluminum bronze work-piece with nickel powder added di-electric fluid. It was noted that the surface achieved by powder-mixed EDM has a small surface roughness, greater resistance to surface wear and more resistance to corrosion. Yan et al. (2001) [33] studied surface alteration of SKD 61 during EDM with mixing of $\mathrm{Al}$ and $\mathrm{Cr}$ powders in the di-electric fluid. The added powder migrated and penetrated into the machined surface which improved the corrosion resistance and hardness of the surface. Simao et al. (2002) [34] experimented on the surface alteration and combined electrical discharge texturing of hardened AISI D2 Sendzimir rolls. They used powder metallurgy green compact and sintered $\mathrm{TiC} / \mathrm{WC} / \mathrm{Co}$ and $\mathrm{WC} / \mathrm{Co}$ tools. An increase in hardness of white layer hardness was noted. It was also found that the change in properties of the tool resulted in the improved texturing performance and less material transfer. Wang et al. (2002) [35] concluded that a hard ceramic coating can be developed on the work-piece using a Ti powder green compact tool. The tool wears and hard carbide was 
formed through the chemical reaction amidst the worn tool and the carbon particles decomposed from dielectric fluid.

Guu et al. (2003) [36] assessed the surface characteristics of AISI D2 tool steel. The results showed that the depth of the re-cast layer and surface roughness were directly related to the power input. Moro et al. (2004) [37] proposed the surface modification application to improve the life of cutting tool by EDM. Bleys et al. (2006) [38] studied the influence of process variables of EDM on surface and sub-surface quality in the manufacture of mold and tool steel. This included surface roughness, sub-surface micro-structure and composition, micro-hardness and residual stresses. Chen et al. (2008) [39] observed output variables for low carbon steel during electrical discharge machining with semi-sintered tools. The surface modifications were also studied. Experimentation confirmed that the material from semi-sintered tool is deposited onto the work-piece to form a modified layer. Hwang et al. (2010) [40] applied layer of Ti-C to the nickel surface by EDC with a multi-layer tool. They observed that higher concentration of carbon in Ti-C resulted in enhanced surface hardness of the coated layer, decreased surface roughness, reduction of micro-cracks and enhanced coating speed.

Janmanee and Muttamara (2012) [41] evaluated the surface alteration of Ti-C by EDC. They used Ti powder mixed in di-electric for carrying out coating process. Less cracks and increased surface hardness were observed. Das and Jain (2013) [26] investigated surface modification of aluminum work-piece by EDC using $\mathrm{TiC} / \mathrm{Cu}$ green compact tool. The material deposition rate increased with the increase in the current, on-time and tool composition. Prakash et al. (2019) [43] coated a composite layer of $\mathrm{TiO}_{2}-\mathrm{TiC}-\mathrm{NbO}-\mathrm{NbC}$ onto the Ti-64 alloy. It was noted that the high peak current and high $\mathrm{Nb}$-powder concentration resulted in enhancement of material migration and a crack-free thick layer on the work-piece was obtained. The surface hardness of the coating is enhanced.

Elaiyarasan et al. (2019) [43] investigated wear behavior of ZE41A magnesium alloy coated with $\mathrm{WC} / \mathrm{Cu}$ by means of EDC. It was observed that that the wear rate and coefficient of friction increased with increment in normal load, sliding speed and sliding time. Elaiyarasan et al. (2019) [44] investigated the impact of the use of WC/Ni powder metallurgy tool on the ZE41A magnesium alloy by EDC. They noted that that the material deposition rate increased with increasing current and on-time. Machkale and Dabade (2020) [45] used powder metallurgy tool of $\mathrm{W}-\mathrm{Cu}$ and AISI 1020 steel work-piece. It was observed that peak current and pulse duration play a main part in the coating performance.

\section{Inferences Drawn from this Study}

This paper reviewed available literature in the domain of surface modification by electrical discharge coating. In the beginning, brief overview of surface modification and various methods used for achieving surface modification are presented. In order to improve high hardness, strength and wear resistance, surface coatings can be promising approach thus making it ideal for tools, die, machine parts and wear resistant equipment. Various advantages and limitation of EDC along with its applicability is also discussed. The literature survey highlighted that a lot of work has been conducted in the area of EDC using powder metallurgical tools and powder mixed di-electric fluids. Above study can be theorized as following.

1. Inverse polarity is more suitable for EDC contrasted with straight polarity.

2. The suspension of powder in di-electric fluid improves the coating characteristics.

3. Through EDC, alteration in the surface properties of the material is achieved. This improves wear resistance, corrosion resistance and biocompatibility.

4. Effect of EDM process variables on deposition rate and deposited coating micro-structure needed detailed exploration.

5. Experimental investigations of effect of density or porosity of tool on surface coating have not been carried in much detail.

6. It was observed that surface modification obtained by EDC is more advantageous than other surface modification methods.

\section{Research Gaps}

Research gaps identified in this study are as given below :

1. Few researchers have investigated effect of using multi-layered electrode on EDC performance. More detailed investigation in this field is required.

2. Research on the use of electrodes developed by 3D printing has been conducted. Though the process of 3D printing, electrodes of various shape and size can be easily printed. All, electrode of same material but variable densities and electrode of multiple material can be developed. Although, the process is limited by cost and material.

3. Investigations on hybrid EDC process for surface modification are very limited. Effect of secondary process on performance of electrical discharge coating can be thoroughly investigated.

\section{Framework for Future Research}

This framework for further research investigation include following steps:

1. The main objective of proposed research work will to study the effect of process variable of EDC on response variable. Work-piece material will be selected on the basis of its application in biomedical field.

2. Suitable process variables will be selected to study their effects on deposition rate, tool wear rate, layer 
thickness, micro- hardness and surface characterization.

3. Variable density electrode of same material will be synthesized by using powder metallurgical technique.

4. Before implementing stepwise $\mathrm{P} / \mathrm{M}$ technique, it is important to select powder material for tool. Single or multiple materials can be used. Using multiple materials can affect the properties of tool.

5. Variable density of electrode can be achieved by varying compact pressure during $\mathrm{P} / \mathrm{M}$ process. Necessary calculation will be done to known the value of compaction pressure required. Lower the density more will be deposition rate.

6. Other parameters of $\mathrm{P} / \mathrm{M}$ process will be selected to synthesis tools.

7. The process parameters will be optimized for the best performance of EDC.

\section{References}

1. M. Y. Khan, P. S. Rao, Int J of Engg and Adv Technol 9, 1059 (2019)

2. M. Y. Khan, P. S. Rao, Int J of Inn Technol and Exploring Engg 8, 1696 (2019)

3. M. Y. Khan, P. S. Rao, B.S. Pabla, Rev of electrical discharge machining process with nanopowder and CNT mixed dielectric fluid, in Proceeding of $4^{\text {th }}$ Int Online Multidisciplinary Research Conference, 23 October 2020, Hyderabad (2020)

4. M. Y. Khan, P. S. Rao, B. S. Pabla, Mater Tod: Proceed, 26, 335 (2020)

5. I. Sen, G. Karthikeyan, J. Ramkumar, R. Balasubramaniam, Mater and Manufac Pro, 27 , 348 (2012)

6. S. Chakraborty, S. Kar, V. Dey, S. K. Ghosh, Sur Rev and Let, 25, 1830003 (2018)

7. S. Vijayakumar, N. Mohan, C. Dineshbabu, G. Karthikeyan, Int J of Mod Tr in Engg and Sc, 3, 184 (2016)

8. J. W. Murray, S. J. Algodi, M. W. Fay, P. D. Brown, A. T. Clare, J of Mater Proces Technol, 243, 143 (2017)

9. S. Kumari, Study of TiC coating on different type steel by electro discharge coating, M.Tech dissertation, National Institute of Technol, Rourkela (2015)

10. P. J. Liew, C. Y. Yap, J. Wang, T. Zhou, J. Yan, Int J of Exte Manufac, 2, 012004 (2020)

11. T. Xue, S. Attarilar, S. Liu, J. Liu, X. Song, L. Li, B. Zhao, Y. Tang, Fron in BioEngg and BioTechnol, 8, 1261 (2020)

12. Y. Oshida, BioScience and BioEngineering of Titanium Materials $2^{\text {nd }}$ edn. (Elsevier, UK, 2007)

13. L. Quintino, Overview of coating technologies. In Surface Modification by Solid State Processing, 1 (Woodhead Publishing 2014)

14. D. S. Verma, A study on Surface modification of Aluminium Al6061 using electric discharge coating, M.E. Dissertation, National Institute of Technical Teachers' Training and Research, Chandigarh (2017)
15. A. A. Siddiqui, A. K. Dubey, Laser Surface Treatment. Engineering Steels and High EntropyAlloys (IntechOpne, UK 2020)

16. J. R. Creighton, P. Ho, Introduction to chemical vapor deposition (CVD). Chemical vapor deposition, 2, 1 (2001)

17. T. Moro, A. Goto, N. Mohri, N. Saito, K. Matsukawa, H. Miyake, J- Japan Soc for Pre Engg 67, 114 (2001)

18. K. H. Watane, M. Gudadhe, Int J of Mech Engg and Inf Technol,2, 614 (2014)

19. D. Tijo, S. Kumari, M. Masanta, Silicon, 10, 1625 (2018)

20. S. Chakraborty, S. Kar, S.K. Ghosh, V. Dey, Surs and Interfac, 7, 47 (2017)

21. R. Tyagi, A.K. Das, A. Mandal, Tribolog Int, 120, 80 (2018)

22. Z. L. Wang, Y. Fang, P. N. Wu, W.S. Zhao, K. Cheng, J of Mater Proces Technol, 129, 139 (2002)

23. R. Bröcking, A. Meghwal, S. Melzer, S. Verdier, G. Evans, T. Lowbridge, J.F. Vanhumbeeck, D. Debrabandere, J. Crahay, Iron Steel Technol, 12, 68 (2015)

24. H. J. Chen, K.L Wu, B. H. Yan, Mater and Manufac Pro, 28, 1286 (2013)

25. C. Prakash, M. S. Uddin, Sur Coating Technol, 326 , $134(2017)$

26. A. Das, N. K. Jain, N. K, Int J of Manufac Technol and Manag, 27, 251 (2013)

27. M. Y. Khan, P. S. Rao, B. S. Pabla, Mater Tod: Proceed (to be published)

28. Y. Fukuzawa, Y. Kojima, E. Sekiguchi, N. Mohori, ISIJ Int, 33, 996 (1993)

29. Y. Tsunekawa, M. Okumiya, N. Mohri, I. Takahashi, Mater Sc and Engg: A, 174, 193 (1994)

30. J. S. Soni, G. Chakraverti, J of Mater Proces Technol,56, 439 (1996)

31. Y. C. Lin, B. H. Yan, F. Y. Huang, J of Mater Proces Technol, 115, 359 (2001)

32. Y. Uno, A. Okada, S. Cetin, Sur modification of EDMed Sur with powder mixed fluid, in Proceedings of $2^{\text {nd }}$ Int Conference on Design and Production of dies and molds.

33. B. H. Yan, Y.C. Lin, F.Y. Huang, C.H. Wang, Mater Transs, 42, 2597 (2001)

34. J. Simao, D. Aspinwall, F. El-Menshawy, K. Meadows, J of Mater Proces Technol, 127, 211 (2002)

35. Z. L. Wang, Y. Fang, P. N. Wu, W.S Zhao, K. Cheng, J of Mater Proces Technol, 129, 139 (2002)

36. Y. H. Guu, H. Hocheng, C. Y. Chou, C. S. Deng, Mater Sc and Engg: A 358, 37 (2003)

37. T. Moro, N. Mohri, H. Otsubo, A. Goto, N. Saito, J of Mater Proces Technol, 149, 65 (2004)

38. P. Bleys, J. P. Kruth, B. Lauwers, B. Schacht, V. Balasubramanian, L. Froyen, J. Van Humbeeck, Adv Engg Mater, 8, 15 (2006)

39. Y. F. Chen, H. M. Chow, Y. C. Lin, C. T. Lin, The Int J of Adv Manufac Technol, 36, 490 (2008)

40. Y. Hwang, C. Kuo, S Hwang, J of Mater Proces Technol, 210, 642 (2010)

41. P. Janmanee, A. Muttamara, Applied Sur Sc. 258, $7255(2012)$ 
42. C. Prakash, S. Singh, C. I. Pruncu, V. Mishra, G. Królczyk, D. Y. Pimenov, A. Pramanik, Mater, 12, 1006 (2019)

43. U. Elaiyarasan, V. Satheeshkumar, C. Senthilkumar, J of Bio-and Tribo-Corr, 5, 30 (2019)

44. U. Elaiyarasan, V. Satheeshkumar, C. Senthilkumar, R. Harishankar, J. Keats Avinash, Int J of Engg and Technol, 7, 1 (2019)

45. P. D. Machkale, B.M. Dabade, Mater Tod: Proceed, 26, 2915 (2020) 